\title{
MENGKAJI TRADISI MEMBANGUN “ORIN TAGAN” MASYARAKAT KAMPUNG NITA KABUPATEN SIKKA
}

\author{
Ambrosius Alfonso Korasony Sevili Gobang \\ Prodi Arsitektur Universitas Nipa Maumere \\ e-mail: aagobangg@gmail.com \\ Emiliana Yulistia Polawati \\ Prodi Arsitektur Universitas Nipa Maumere \\ e-mail: pow17@gmail.com
}

\begin{abstract}
ABSTRAK
Rumah berbentuk panggung yang disebut "Orin Tagan" yaitu rumah yang memiliki kolong (lewu) atau panggung setinggi 1 meter. Sehubungan terjadinya interaksi dari budaya yang berbeda dan menetap di satu Pulau Flores, maka unsur-unsur budaya yang dapat berpengaruh satu terhadap yang lain. Salah unsurnya berupa tradisi membangun. Penelitian tentang tradisi membangun rumah masyarakat kampung Nita sangat sedikit. Sehingga dicari beberapa penelitian berdasarkan tema sejenis (tema: tradisi membangun) dan lokasi sejenis (lokasi: Kampung Nita, Kabupaten Sikka). Rumusan masalah penelitian ini adalah untuk memahami bagaimana tradisi membangun "orin tagan" oleh masyarakat Kampung Nita. Tujuan penelitian ini adalah untuk memahami tradisi membangun "orin tagan" oleh masyarakat Kampung Nita dengan membentuk sebuah diagram unsur pembentuk. Strategi penelitian bersifat deskriptif/naratif. Metode pengumpulan data bersifat kualitatif. Data primer diambil berdasarkan hasil wawancara mendalam dengan: undagi (arsitek kampung/tukang) dan tokoh masyarakat. Metode analisis data terdiri atas: (1) analisis paticipants meaning dan (2) analisis sistem struktur dan (3) analisis sistem tampilan. Hasil penelitian yang diharapkan adalah berupa diagram yang berisi unsurunsur yang membentuk struktur rumah panggung (orin tagan) pada masyarakat Kampung Nita Kabupaten Sika, yaitu sistem struktur dan sistem tampilan. Unsur pembentuk sistem struktur terdiri atas: struktur atap, dinding dan pondasi. Unsur pembentuk sistem sistem tampilan terdiri atas: tampilan teras dan tampilan kusen.
\end{abstract}

Kata kunci: rumah kolong, tradisi membangun, sistem struktur, sistem tampilan

\begin{abstract}
Stage-shaped house called "Orin Tagan" is a house that has a pit (lewu) or a stage as high as 1 meter. In connection with the interaction of different cultures and settled on one island of Flores, the cultural elements that can affect one another. One element is in the form of a building tradition. There is very little research on the tradition of building houses in the Nita village community. So some researches are sought based on similar themes (theme: building tradition) and similar locations (location: Kampung Nita, Sikka Regency). The research problem formulation is to understand how the
\end{abstract}

PAWON: Jurnal Arsitektur, Nomor 01 Volume IV, Bulan Januari-Juni Tahun 2020, ISSN 2597-7636 
tradition of building "orin tagan" by the people of Kampung Nita. The purpose of this study is to understand the tradition of building "orin tagan" by the people of Kampung Nita by forming a constituent element diagram. The research strategy is descriptive / narrative. Data collection methods are qualitative. Primary data was taken based on the results of in-depth interviews with: undagi (village architect / handyman) and community leaders. Data analysis methods consist of: (1) paticipants meaning analysis and (2) structural system analysis and (3) display system analysis. The expected research results are in the form of diagrams containing elements that make up the structure of the stage house (orin tagan) in the community of Kampung Nita, Sika Regency, namely the structural system and display system. The building blocks of the structural system consist of: roof, wall and foundation structures. The forming elements of the display system consist of: terrace display and frame display.

Keywords: underneath house, building tradition, structural system, display system

\section{PENDAHULUAN}

Terdapat tiga sistem dalam mengelompokkan wujud arsitektur, yaitu: sistem spasial (spatial system), sistem fisik (physical system), sistem model atau tampilan (stylictic system) (Habraken, 1978). Penelitian ini membahas mengenai sistem fisik dan sistem tampilan yang merupakan bagian dari pengkajian tradisi membangun rumah masyarakat adat kampung Nita.

Penelitian ini mengkaji tradisi membangun rumah panggung (orin tagan) masyarakat adat kampung Nita kabupaten Sikka. Rumah berbentuk panggung yang disebut "Orin Tagan" yaitu rumah memiliki kolong (lewu) atau panggung setinggi 1 meter dengan maksud agar ada ruang yang lebih luas memungkinkan orang dapat masuk di bagian bawah rumah (tama logu ele dugi). Tradisi membangun orin tagan adalah salah satu ciri masyarakat adat kampung Nita.

Penelitian yang mengkaji tradisi membangun rumah masyarakat adat kampung Nita masih sangat sedikit. Untuk menunjang penelitian, dicari beberapa penelitian tema sejenis (tema: tradisi membangun) dan penelitian lokasi sejenis (lokasi: Kampung Nita, Kabupaten Sikka). Berikut beberapa penelitian tentang tema sejenis (tema: tradisi membangun), yaitu: (Asriany, 2016 ); (Rosyadi, 2015). Berikut beberapa penelitian lokasi sejenis (lokasi: Kampung Nita, Kabupaten Sikka): (Kian, Rayawulan, Mberu, \& Lily, 2018); (Gobang, 2014).

Ibu kota Kecamatan Nita adalah Kecamatan Nita yang terletak di 283 diatas permukaan laut (DPL) dengan luas $141.07 \mathrm{~km}^{2}$ dengan prosentase sebesar $8.15 \%$ (BPS, 2018). Sehubungan dengan terjadinya interaksi antara orang-orang yang berasal dari budaya yang berbeda dan menetap di satu wilayah atau pulau yang sama, yakni Pulau Flores, maka unsur-unsur budaya 
yang dapat berpengaruh satu terhadap yang lain adalah: pandangan dan tujuan hidup, konsep diri, norma dan aturan, bahasa (verbal dan nonverbal), konsep waktu, sejarah, mitologi, seni, lembaga sosial, dan artefak. Pulau Timor dan sekitarnya (termasuk Flores tentu saja) sebagai daerah melting point atau tempat peleburan berbagai suku bangsa (Kleden dalam (Gobang, 2014).

Rumah tinggal di Maumere menurut Paul Arndt, SVD dalam bukunya Hubungan Kemasyarakat Sikka Tahun 1963, bagian rumah di Maumere terdiri dari dua bagian utama, tedang (serambi) dan une (ruangan dalam). Kedua bagian ini dibagi lagi menjadi beberapa bagian dengan dinding pelupuh. Di beberapa wilayah bagian ini berbeda-bea dan mempunyai nama yang berbeda pula. Di daerah Wolokoli pada umunya serambi mempunyai tiga bagian: tedang, tedang gete dan seka poar. Tedang adalah ruang tidur untuk laki-laki dewasa dan hamba-hamba lelaki; tedang gete adalah ruang tidur anak-anak perempuan dewasa dan nenek (nenek yang sudah janda); sedangkan seka poar digunakan untuk beristirahat. Bagain dalam dibagi dalam dua ruangan yang besar, yang satu disebut une gete yaitu ruang tidur untuk orang tua dan anak-anak yang masih kecil dan yang kedua disebut bilik kolor yaitu kamar tidur untuk kakek nenek atau untuk perempuan dewasa. Di daerah Nita anak-anak perempuan dewasa boleh tidur di kamar orang tua. Di antara kedua kamar itu ada sebuah ruangan kosong yang dipakai untuk melahirkan anak atau membaringkan orang sakit atau keperluan semacam itu. Di samping ketiga ruangan ini ada sebuah lorong dan di ujung lorong tersebut ada kamar berukuran kecil untuk dipakai oleh kakek/nenek atau satu keluarga lagi. Di wilayah Barat Maumere terdapat rumah-rumah yang jauh lebih besar dan terdapat lebih banyak kamar untuk tempat tinggal beberapa keluarga seperti anak laki-laki bersama dan istri dan anak-anaknya dan didiami oleh lima keluarga; jadi memuat sampai lima puluh orang dalam satu rumah. Segala kepunyaan keluarga-keluarga terpisah, masing-masing mempunyai urusan rumah tangga dan ladang terpisah dari kepunyaan keluarga lainnya. Rumah di Tana'Ai terdiri dari satu ruang yang besar yang tidak dibagi-bagi. Pada umumnya masing-masing orang mempunyai tempat tersendiri untuk tidur dengan nama-nama seperti: une gete yaitu tempat tidur untuk orang tua, suku untuk kakek dan nenek, tepi untuk anak-anak. Anakanak perempuan tidur bersama nenek (suku wiri), anak laki-laki tidur bersama kakek (suku wana). Para hamba tinggal di luar rumah, di woga tedang (serambi). Di rumah ini beberapa keluarga dapat tinggal bersama,masingmasing mempunyai ladangnya sendiri tetapi hasilnya kerap kali dikumpulkan dan digunakan bersama.

PAWON: Jurnal Arsitektur, Nomor 01 Volume IV, Bulan Januari-Juni Tahun 2020, ISSN 2597-7636 


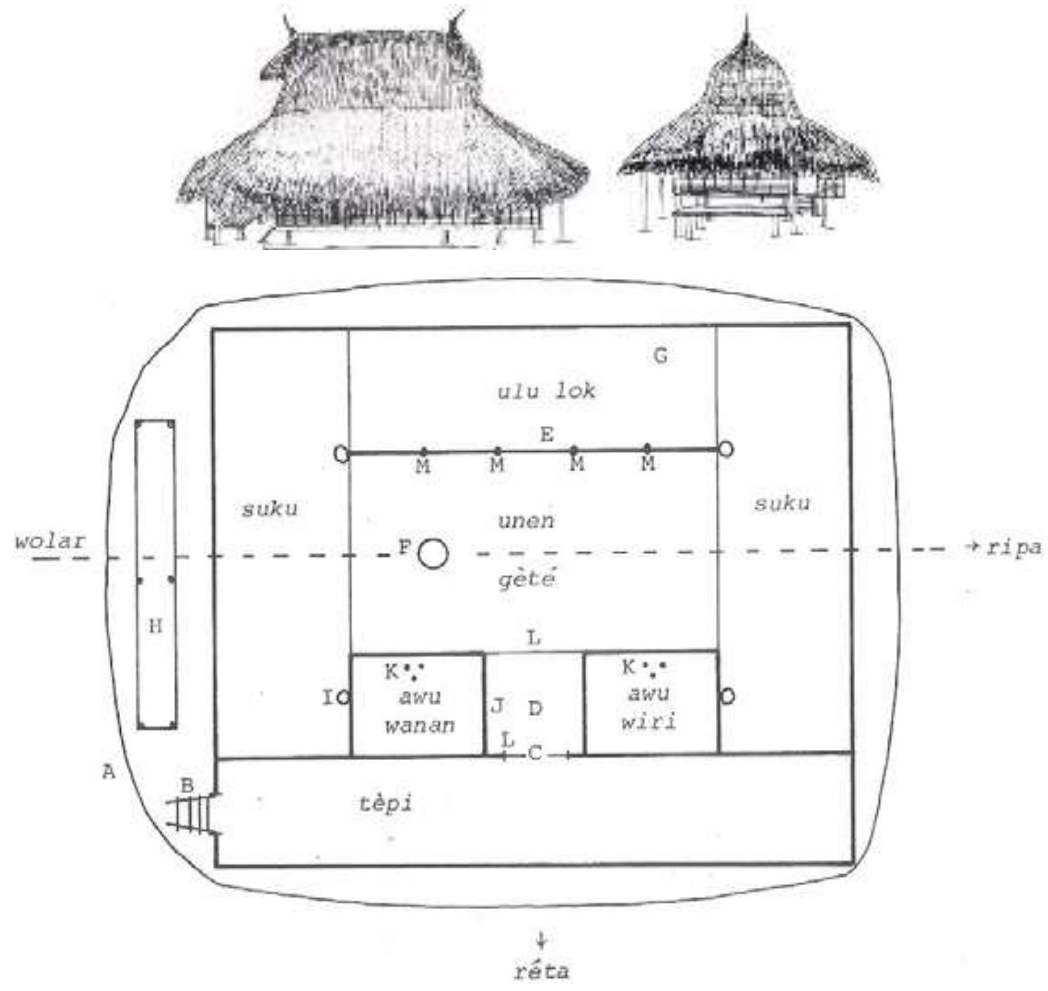

Gambar 1.

Tampak dan Denah Rumah Orin Tagan

Rumusan masalah penelitian ini bagaimana tradisi membangun rumah panggung (orin tagan) masyarakat adat kampung Nita kabupaten Sikka? Sedangkan tujuan penelitian ini adalah berusaha mengkaji tradisi membangun rumah panggung (orin tagan) masyarakat adat kampung Nita kabupaten Sikka dalam bentuk kajian berbentuk diagram.

\section{TINJAUAN PUSTAKA}

Tinjauan pustaka membahas mengenai empat hal yaitu: (1) sistem perwujudan arsitektur, (2) masyarakat adat secara umum, (3) tradisi membangun secara umum (4) tradisi membangun masyarakat Sikka.

\subsection{Sistem Fisik, Sistem Tampilan dan Sistem Spasial}

Sistem spasial (spatial system) yaitu berkaitan dengan ruang yang meliputi organisasi, orientasi dan hirarki ruang. Sistem fisik / struktur (physical system) yaitu yang berkaitan dengan penggunaan material konstruksi penyusun bangunan seperti atap, dinding, lantai dan kolom yang digunakan dalam mewujudkan suatu fisik bangunan. Sistem model / tampilan (stylictic system) yaitu berkaitan dengan tampak depan atau fasade meliputi pintu, jendela, ventilasi dan ragam hias (Habraken, 1978). 


\subsection{Masyarakat Adat}

Pada akhir 1980-an dan awal 1990-an, kelompok-kelompok gerakan lingkungan dan HAM di Indonesia dan gerakan indigenous peoples di dunia internasional, mengusung istilah indigenous peoples yang dapat dipadankan dengan istilah 'masyarakat adat'. Istilah ini lebih mengakomodir dimensi kultural dan religius kelompok masyarakat yang dimaksud dan tidak mempersempitnya menjadi sekadar sebuah entitas hukum belaka (Rosyadi, 2015).

Barnes, Gray and Kingsbury (1995) dalam Rosyidi (2015) merumuskan definisi indigenous peoples, yaitu: (1) Self-definition (otonomi dalam mendefinisikan diri sendiri); (2) Historical continuity (kesinambungan sejarah masa lampau); (3) Non-dominance sector of society (kelompok masyarakat yang tidak dominan dalam keseluruhan masyarakat bangsa); (4) Ancestral territories (wilayah yang diidentifikasi sebagai warisan leluhur atau nenek moyang dari kelompok tersebut); (5) Ethnic identity (adanya pertalian etnis dalam kelompok masyarakat tersebut)

Abdul Latif (2011) dalam Rosyidi (2015) mendefinisikan masyarakat adat sebagai: kelompok masyarakat yang hidup dalam suatu wilayah geografis tertentu dalam kurun waktu yang relatif lama, terikat pada tradisi dan adat istiadat yang diwarisi dari leluhurnya, di antara para warganya satu sama lain terikat dalam hubungan kekerabatan. Pada umumnya mereka memiliki lembaga adat yang dipimpin oleh seorang ketua adat. Kepemimpinan ketua adat biasanya diwariskan secara turun-temurun, atau melalui ketentuan adat tertentu. Adapun yang dimaksud dengan lingkungan geografis adalah lingkungan alam di mana mereka hidup. Komunitas adat di Jawa Barat pada umumnya hidup di pedalaman, atau daerah pegunungan. Mereka mengandalkan hidupnya dari sektor pertanian, yaitu bersawah, berladang, dan berkebun.

Ade Makmur K. (2009) dalam Rosyidi (2015) mendefinisikan Indigenous Peoples, adalah pewaris dan pelaksana kebudayaan yang unik dan bentuk-bentuk hubungan dengan sesama manusia dan lingkungan, dengan mempertahankan sifat-sifat sosial, ekonomi dan politiknya yang berbeda dengan masyarakat pada umumnya di mana mereka tinggal. Merujuk pada definisi masyarakat adat oleh PBB tersebut, dalam konteks Indonesia setidaknya dikenal tiga kategori masyarakat adat, yaitu:

- Kelompok sosial yang terikat oleh tradisi, namun tidak terikat oleh kesatuan tempat tinggal yang sama.

- Kelompok sosial yang terikat oleh tradisi dan masih mengamalkan ketentuan leluhur, tetapi diberi kelonggaran memilih kesatuan tempat tinggal.

- Kelompok sosial yang terikat, dan menjalankan tradisi leluhur dengan ketat, serta terikat oleh kesatuan tempat tinggal yang sama dalam kelompok-kelompok yang kecil.

PAWON: Jurnal Arsitektur, Nomor 01 Volume IV, Bulan Januari-Juni Tahun 2020, ISSN 2597-7636 
Dari ketiga kategori tersebut, kategori kesatu dan kedua lebih dikenal sebagai masyarakat tradisional dan kategori ketiga dikenal sebagai masyarakat adat. Adapun sebutan yang umum bagi mereka yang termasuk kategori tiga, dikenal dengan pelbagai istilah: seperti orang gunung (highlanders), orang asli (aborigines), orang hutan (forest people), pribumi (natives), dan masyarakat terasing (komunitas adat terpencil).

\subsection{Tradisi Membangun}

Tradisi membangun dalam arsitektur tradisional di Indonesia menjadi sebuah tradisi utama dalam menentukan keberlanjutan dari kebudayaan masyarakat setempat (Asriany, 2016 ). Bagi masyarakat nusantara dalam pendekatan mikro kosmos adalah bahwa seluruh aktivitas akan bertumpu pada rumah. Kondisi sosial budaya akan selalu tergambar dalam tradisi membangun dan mendirikan sebuah rumah.

Arsitektur di nusantara umumnya memiliki perwujudan bentuk tubuh manusia yang terbagi dalam tiga bagian utama, yaitu:

- Kepala, diibaratkan sebagai kepala manusia yang merupakan bagian tertinggi dan paling penting peranannya dalam struktur tubuh manusia.

- Badan, diibaratkan sebagai badan manusia. Badan bangunan merupakan inti bangunan yang meliputi: dinding dan ruang-ruang yang terdiri dari sistem konstruksi, bahan/ material, ornamen, dan pola penataan ruang.

- Kaki, diibaratkan kaki manusia untuk bertumpu. Kaki bangunan ini meliputi pondasi

Dalam masyarakat nusatara setidaknya terdapat: tradisi sebelum mendirikan bangunan dan tradisi setelah mendirikan bangunan.

\subsection{Tradisi Membangun Masyarakat Adat Desa Nita}

Ciri utama pembangunan di desa berdasarkan tradisi dan budaya yang berkembang dari masa ke masa adalah berazaskan musyawarah dan prinsip kebersamaan gotong royong. Gotong-royong sebagai pola hidup bersama yang menjunjung tinggi asas solidaritas dan fraternitas, serta musyawarah sebagai model komunike partisipatif yang melibatkan semua golongan masyarakat dalam perencanaan dan pelaksanaan pembangunan.

Dalam kehidupan masyarakat Desa Nita pada umumnya sampai dengan saat ini, kebiasaan gotong royong dan musyawarah bersama masih dipertahankan dan terpelihara baik dalam pelbagai bidang kehidupan, secara khusus dalam proses pengambilan kebijakan serta perencanaan dan pelaksanaan pembangunan desa. Pola hidup gotong royong dan musyawarah itu dapat dilihat dari:

- Kebiasaan gotong royong dalam pengerjaan kebun dan penggarapan lahan,kegiatan bhakti desa, pembangunan rumah warga atau sa 
rana prasarana umum lainnya yang dikenal dengan istilah 'Sako Seng' atau 'Lahi Lekang'.

- Kebiasaan partisipatif dalam komunitas adat dan kehidupan bersama ketika menghadapi peristiwa kematian, kelahiran, perkawinan dan musibah melalui cara dan upaya saling mengajak atau 'Gaging Gatang', saling mengunjungi atau 'Dulu Dalang' dan dalam ikatan persahabatan atau 'Imung Deung'.

- Kebijakan melalui musyawarah mufakat untukpengambilan keputusan dalam pelbagai kegiatan bersama serta penyelesaian masalah publik lainnya melalui komunike 'Kula Babong' atau 'Bibo Babong' bersama.

\section{METODE PENELITIAN}

\subsection{Strategi Penelitian}

Penelitian ini menggunakan strategi yang bersifat deskriptif / naratif. Penelitian naratif merupakan strategi penelitian di mana di dalamnya peneliti menyelidiki kehidupan individu-individu dan meminta seorang atau sekolompok individu untuk menceritakan kehidupan mereka. Informasi ini kemudian diceritakan kembali oleh peneliti dalam kronologi naratif. Di akhir tahap penelitian, peneliti harus menggabungkan dengan gaya naratif pandangan-pandangannya tentang kehidupan partisipan dengan pandanganpandangannya tentang kehidupan peneliti sendiri (Cresswell, 2012).

\subsection{Metode Pengumpulan Data}

Metode pengumpulan data bersifat kualitatif (bukan kuantitatif). Tujuan penelitian kualitatif pada umumnya mencakup informasi tentang fenomena utama yang dieksplorasi dalam penelitian, partisipan penelitian, dan lokasi penelitian. Tujuan penelitian kualitatif juga bisa menyatakan rancangan penelitian yang dipilih. Tujuan ini ditulis dengan istilah-istilah "teknis" penelitian yang bersumber dari bahasa penelitian kualitatif (Cresswell, 2012).

Karena penelitian bersifat kualitatif, maka metode pengumpulan data didapat dari sumber primer yaitu: wawancara mendalam dan observasi lapangan. Wawancara mendalam adalah wawancara inilah di-dapati pernyataan bahwa "wawancara juga digunakan untuk meng-eksplorasi lebih detail variabel-variabel yang sudah dianalisis dan untuk mengtriangulasi hasil penelitian berdasarkan data kuantitatif dan data kualitatif" (Hossler \& Vesper, 1993 dalam Creswell, 2012). Observasi lapangan pada penelitian arsitektural terdiri dari pengukuran arsitektural, sketsa arsitektural dan dokumentasi arsitektural (Febrianto, Wulandari, \& Santosa, 2017). Wawancara mendalam dilakukan pada undagi atau arsitek kampung (Bapak Fransiskus Uni) dan tokoh masyarakat (Bapak Viktor Nekur).

\subsection{Metode Analisis Data}

Metode analisis data terdiri atas: (1) analisis paticipants meaning dan (2) analisis sistem struktur dan (3) analisis sistem tampilan. 


\subsubsection{Analisis paticipants meaning}

Makna dari para partisipan (paticipants meaning); dalam keseluruhan proses penelitian kualitatif, peneliti terus fokus pada usaha mempelajari makna yang disampaikan para partisipan tentang masalah atau isu penelitian, bukan makna yang disampaikan oleh peneliti atau penulis lain dalam literaturliteratur tertentu.

\subsubsection{Analisis Sistem Struktur}

Analisis struktur / sistem fisik (physical system) merupakan hasil observasi, pengukuran dan dokumentasi lapangan yang berkaitan dengan penggunaan material konstruksi penyusun bangunan seperti atap, dinding, lantai dan kolom yang digunakan dalam mewujudkan suatu fisik bangunan (Habraken, 1978). Analisis sistem struktur pada "orin tagan" masyarakat Kampung Nita Kabupaten Sikka terdiri atas: (a) analisis struktur atap, (b) analisis struktur dinding dan (c) analisis struktur pondasi.

\subsubsection{Analisis Sistem Tampilan}

Analisis sistem model / sistem tampilan (stylictic system) yaitu berkaitan dengan merupakan hasil observasi, pengukuran dan dokumentasi lapangan yang berkaitan dengan tampak depan atau fasade meliputi pintu, jendela, ventilasi dan ragam hias (Habraken, 1978). Analisis sistem tampilan pada "orin tagan" masyarakat Kampung Nita Kabupaten Sikka terdiri atas: (a) analisis tampilan teras dan (b) analisis tampilan kusen.

\section{HASIL DAN PEMBAHASAN}

\subsection{Gambaran Umum Kampung Nita}

Menurut sejarah tertulis dan tradisi lisan yang berkembang dari waktu ke waktu, alkisah nama 'Nita' berasal dan diambil dari nama sebuah pohon besar yang tumbuh di tengah-tengah perkampungan bernama pohon Nita. Di bawah naungan pohon inilah pada zaman dahulu kala menjadi tempat berteduh atau istirahat bahkan menjadi 'terminal antar kampung', termasuk menjadi pasar atau tempat jual beli antar warga kampung pada masa itu.

Nama pohon dan tempat itu kemudian secara turun temurun dan dari masa ke masa dalam penyebutan lazim E'i Nita, Lau Nita, Le Nita, Wali Nita, Wawa Nita atau Reta Nita,untuk menunjukan tempat asal dan tujuan perjalanan atau tempat perhentian warga yang kemudian lazim disebut Natar Nita. Inilah asal muasal dari penamaan Kampung Nita atau Desa Nita dengan Pohon Nita sebagai simbol nama dan sejarah penyebutannya. Untuk melestarikan simbol Desa Nita tersebut, maka pada tanggal 08 Januari 2014, telah ditanam sebatang Pohon Nita di halaman Kantor Desa Nita melalui seremoni adat sederhana sebagai tanda lestari budaya dan deskripsi simbolik Desa Nita agar diketahui dan tidak dilupakan oleh generasi sekarang dan yang akan datang 
Masyarakat penutur bahasa Sikka tergolong masyarakat agraris karena sebagian besar adalah petani seperti kelapa, cengkeh, jagung, dan sebagainya. Sebagian dari mereka masih menggunakan sistern pertanian tradisional. Para pegawai hidup di kota-kota, sedangkan pelaut (nelayan) rnendiami daerah pantai. Masyarakat tradisional masih menganut pula sistem sosial lama dengan menempatkan para tuan tanah dan kepala adat sebagai pemimpin tradisional / informal misalnya dalam berbagai kegiatan pertanian. Namun, sistem sosial tersebut pada masa mutakhir ini sudah banyak berubah. Di samping itu, tidak tampak ciri lingual yang menandai sistem sosial tersebut.

Suku berasal dari kata bahasa Portugis, Suco yang berarti satu kesatuan warga atau orang perorangan yang tinggal dan menetap dalam suatu ruang lingkup keluarga atau wilayah tertentu, dipimpin oleh seorang Chefe Suco atau kepala suku sebagai penatua arif yang memimpin keberadaan sebuah suku secara turun temurun dan berkelanjutan. Pada masa sekarang di Desa Nita telah terbentuk Lembaga Adat Desa dengan keanggotaannya yang terdiri dari wakil setiap lepo atau suku-suku tersebut diatas dengan nama Lembaga Adat Watu Pitu. Pada tahun 1958, terbentuklah Pemerintahan Kabupaten Sikka dan Hamente Nita menjadi Kecamatan Nita dengan Camat Pertamanya Philipus Muda Meak da Silva dan yang menjadi Kepala Kampung Nita pada saat itu adalah Hendrikus Gleko Kolit.

Adapun penduduk Nita pada waktu itu hidup berkelompok atau disebut 'kloang' dalam satu kesatuan adat atau suku dengan rumah adat bersama yang disebut 'lepo' dan dikepalai oleh seorang kepala suku. Dari 'kloang' atau 'suku' dan 'lepo' inilah yang membentuk satu kesatuan yang disebut 'Natar' atau Kampung dibawah pimpinan Kepala Kampung. Dari catatan sejarah dan cerita lisan berkembang, tercatat kurang lebih 7 (tujuh) suku atau lepo yang hidup dan berkembang pada masa itu sampai dengan sekarang seperti; Lepo Gete (Ratu/Raja), Lepo Kolit, Lepo Degodona, Lepo Geronpun, Lepo Lorat, Lepo Orin Bao dan Lepo Tour Orin Gete (http://nita.desa.id/beranda/profil/ sejarah/).

Tradisi membangun orin tagan masyarakat adat kampung Nita. berkaitan dengan :

- Lingkungan sekitar

- Halaman/pekarangan

- Politik/hirarki dalam masyarakat dan keluarga

- Leluhur, kepercayaan animisme dan alam.

- Agama (kepercayaan Katolik)

\subsection{Analisis Sistem Fisik / Struktur}

Sistem fisik / struktur (physical system) yaitu yang berkaitan dengan penggunaan material konstruksi penyusun bangunan seperti atap, dinding,

PAWON: Jurnal Arsitektur, Nomor 01 Volume IV, Bulan Januari-Juni Tahun 2020, ISSN 2597-7636 
lantai dan kolom yang digunakan dalam mewujudkan suatu fisik bangunan (Habraken, 1978)

\subsubsection{Analisis struktur atap}

Tradisi dalam pemasangan atap rumah pada "orin tagan" masyarakat kampung nita kabupaten Sikka adalah:

- Bahan untuk atap rumah terbuat dari alang-alang (ri'i) atau daun kelapa ("lepa).

- Alang-alang atau daun kelapa dianyam/diikat memanjang menyerupai seng disebut 'liwar' merupakan cara memudahkan pemasangan atap dengan bahan ini.
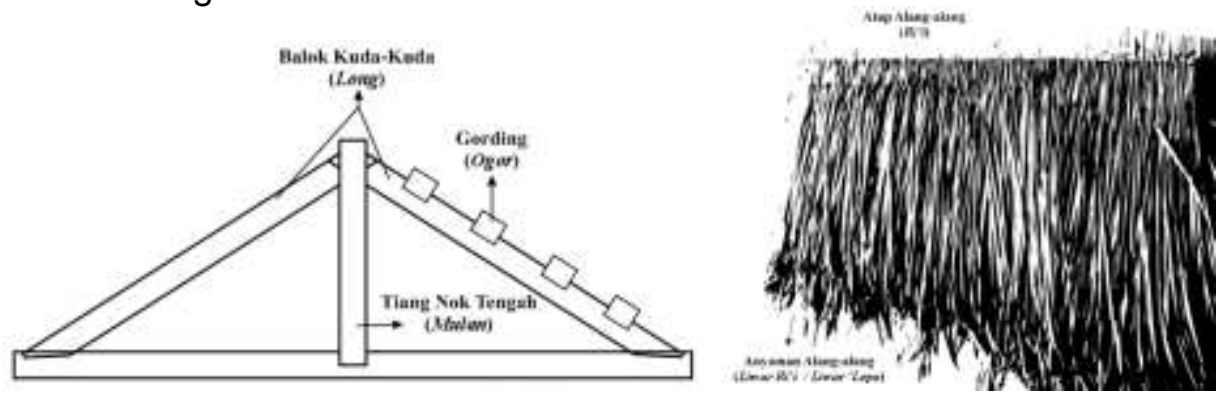

Gambar 2.

Sistem struktur atap

Sumber: dokumentasi pribadi, 2019

\subsubsection{Analisis struktur dinding}

Dinding (gebi) menggunakan beberapa bahan antara lain : papan kayu, pelepu (halar), ayaman bambu ('wire) atau gedeg (gebi 'ranan).

Penempatan jendela di tengah di bagian sisi lebar rumah. Kusen jendela disambung/diikat sampai balok (ihi du'a).

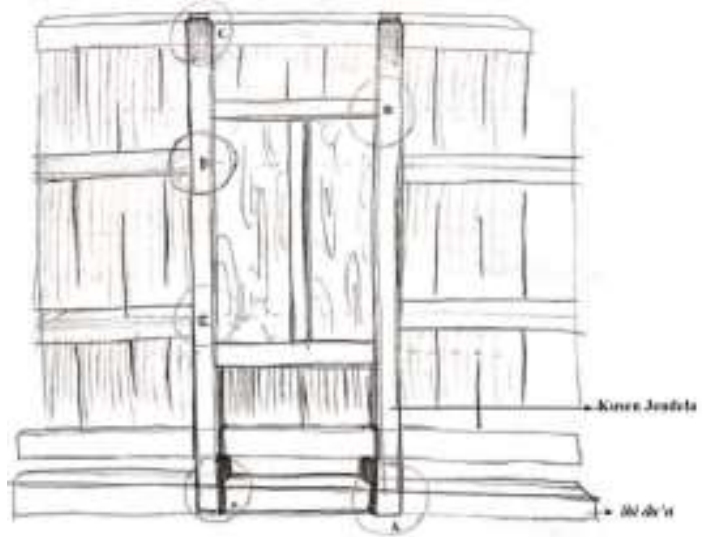

Gambar 3.

Sistem struktur dinding

Sumber: dokumentasi pribadi, 2019

Jurnal PAWON, Nomor -- Volume --, Bulan Tahun, ISSN xxxx-xxxx 
Berikut terdapat dua versi denah orin tagan berdasarkan struktur dinding dan jenis atap. Pada gambar 1 (kiri) adalah versi selasar tanpa atap dan tanpa sekat. Pada gambar 2 (kanan) adalah selasar versi dengan atap dan dilapisi sekat.

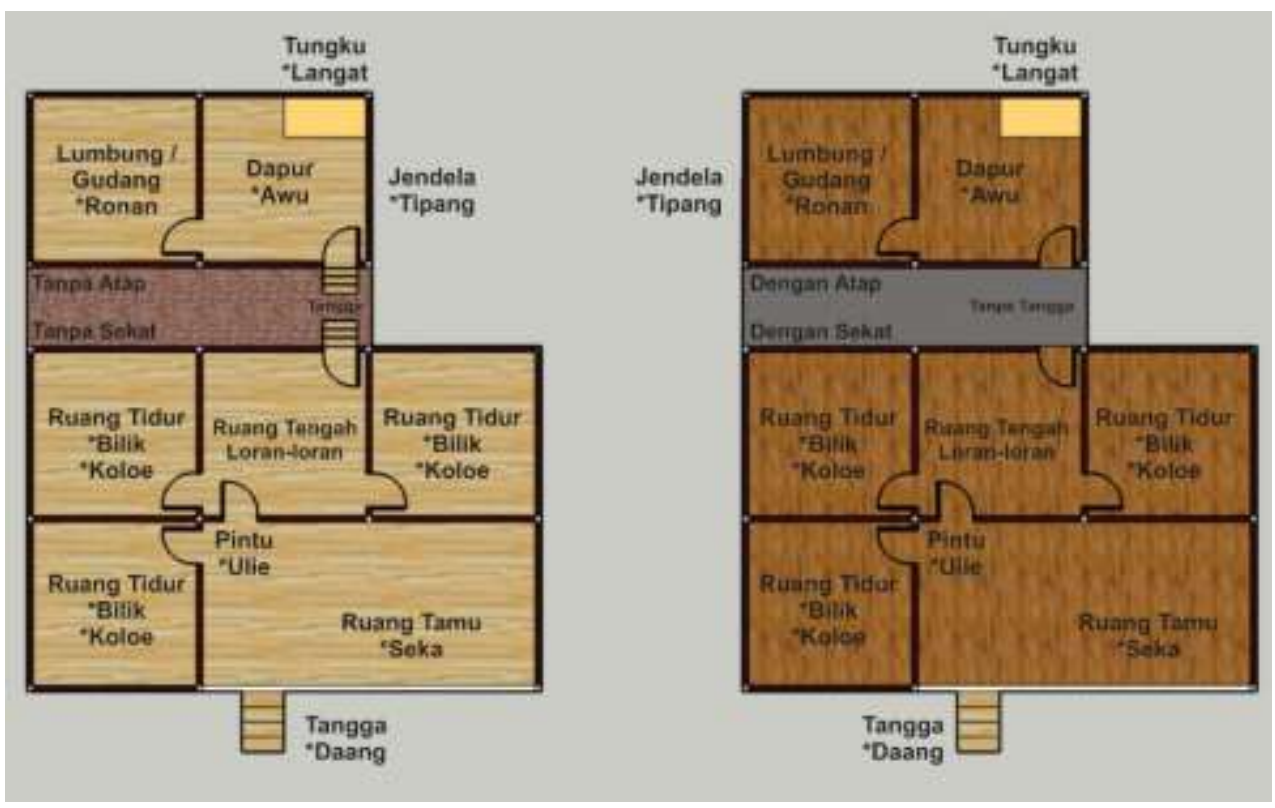

Gambar 4.

Dua versi Denah "orin tagan"

Sumber: dokumentasi pribadi, 2019

\subsubsection{Analisis struktur pondasi}

Pondasi rumah berbentuk umpak berupa batuan lonjong setinggi 0,5 meter sebagai tumpuan kolom. Berikut adalah dokumentasi salah satu 'orin tagan'yang masih ada yang sudah terdapat sentuhan modernisasi yaitu pada bahan atap dan pondasi umpak. Bentuk orin tagan ini sudah mengalami perubahan, tidak memiliki teras (seka/tedang). Orin tagan sejatinya adalah rumah bagi warga kampung, sedangkan rumah untuk para bangsawan di kampung Nita adalah 'lepo ihin niur'.

PAWON: Jurnal Arsitektur, Nomor 01 Volume IV, Bulan Januari-Juni Tahun 2020, ISSN 2597-7636 

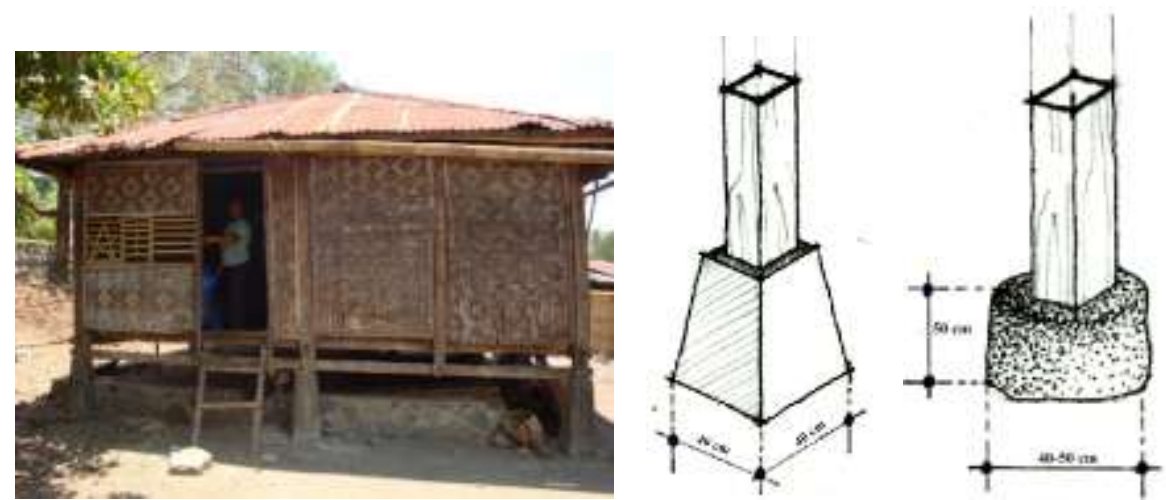

Gambar 5.

Sistem struktur pondasi

Sumber: dokumentasi pribadi, 2019

\subsection{Analisis Sistem Tampilan}

Sistem model / tampilan (stylictic system) yaitu berkaitan dengan tampak depan atau fasade meliputi pintu, jendela, ventilasi dan ragam hias (Habraken, 1978).

\subsubsection{Analisis Tampilan Teras}

Sebelum memasuki rumah, kaki terlebih dahulu akan menginjak batu ceper yang terletak di tanah, kemudian menaiki tangga (dang) selanjutnya mengebaskan kaki (tegar wain) di tempat kebasan (kledar). Tangga (dang) terdapat pula di bagian belakang, jika dapur dibangun terpisah dari rumah induk, maka dapur tidak berbentuk panggung. Anak tangga (dang 'anak) harus ganjil, karena akan digenapi oleh penghuni yang menggunakan tangga (dang).

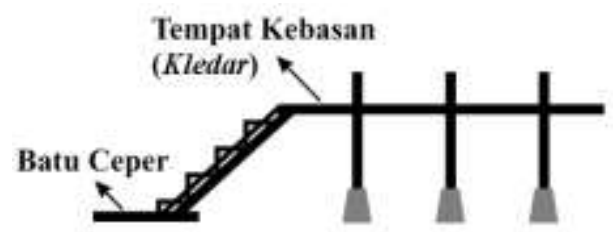

Gambar 6.

Sistem tampilan teras

Sumber: dokumentasi pribadi, 2019

\subsubsection{Analisis Tampilan Kusen}

Kusen pintu tidak boleh tempel langsung dengan kolom, karena tradisi memaknai rumah dengan kusen pintu menempel di kolom akan membuat penghuni sangat sulit menemukan solusi dalam menghadapi persoalan/masalah hidup. Posisi pintu juga tidak boleh tepat di bawah balok kuda-kuda (long), karena tradisi memaknai bahwa penghuni akan sangat sering mendapatkan masalah besar dan berat di dalam kehidupannya. 


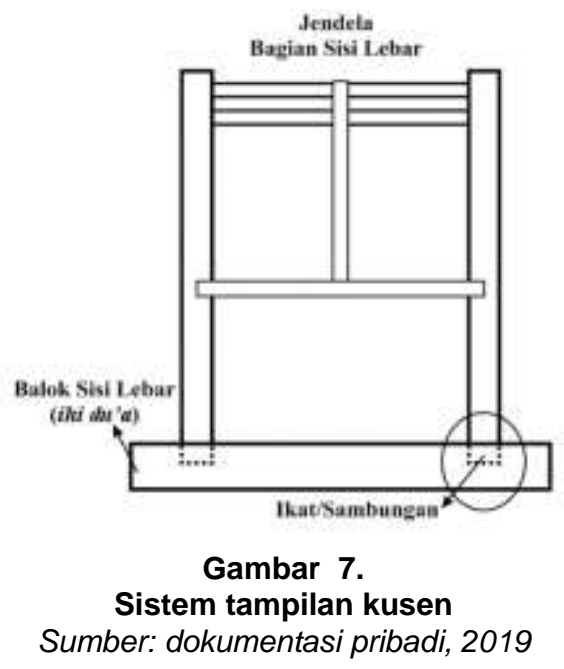

\section{KESIMPULAN}

Tradisi membangun orin tagan (rumah panggung) masyarakat adat kampung Nita kabupaten Sikka dilihat pada 2 sistem perwujudan arsitektur yaitu: (A) sistem fisik / struktur dan (B) sistem tampilan / model. Sistem tesebut merupakan dua dari tiga sistem yang merupakan konsep dari Habraken (1978). Sistem struktur sendiri terdiri atas struktur atap, struktur dinding dan struktur pondasi. Sedangkan sistem tampilan terdiri atas tamilan kusen dan tampilan teras.

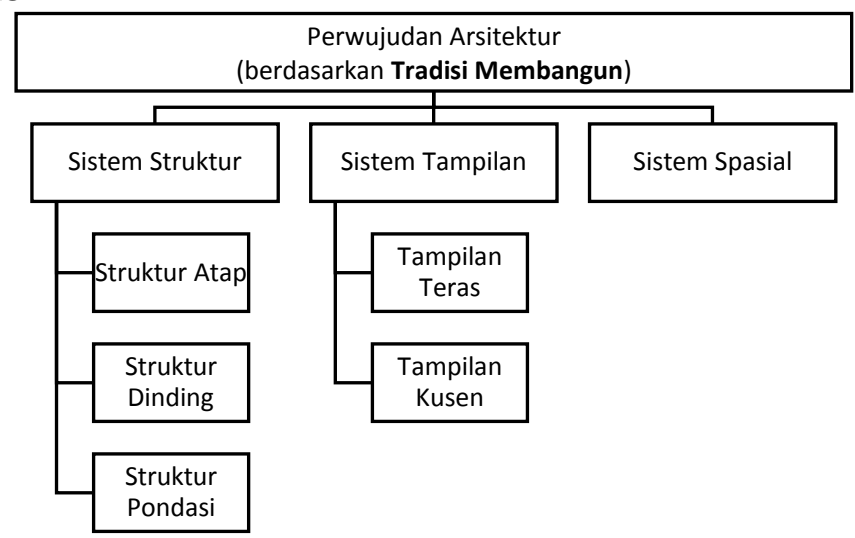

Gambar 8.

Diagram Unsur Pembentuk Tradisi Membangun

Sumber: Analisis pribadi, 2019

PAWON: Jurnal Arsitektur, Nomor 01 Volume IV, Bulan Januari-Juni Tahun 2020, ISSN 2597-7636 


\section{DAFTAR PUSTAKA}

Asriany, S. (2016 ). Tradisi Membangun Arsitektur Tradisional Folajiku Sorabi,

Tidore Kepulauan. Prosiding Temu IImiah IPLBI 2016 (pp. 151-156).

Malang: Ikatan Peneliti Lingkungan Binaan (IPLBI).

BPS. (2018). Kabupaten Sikka Dalam Angka 2018. Maumere: BPS Kab. Sikka.

Cresswell, J. (2012). Eduactional Research: Planning, Conducting, and Evaluating Quantitative and Qualitative Research. Ney Jersey: Person Education, Inc.

Febrianto, R. S., Wulandari, L. D., \& Santosa, H. (2017). Domain Ruang Perempuan Pada Hunian Masyarakat Peladang Desa Juruan Laok Madura Timur. Jurnal Tesa Arsitektur Vol. 15, No. 1.

Gobang, J. K. (2014). Konflik Budaya Lokal Pada Masyarakat di Pulau Flores (Sebuah Analisis Komunikasi Lintas Budaya). Jurnal komunikasi, Vol. 9, No. 1, Oktober 2014, 59-68.

Habraken, N. J. (1978). General Principles A Bout the Way Built Environment Exist. Massachusetts: MIT Press.

Kian, D. A., Rayawulan, R. M., Mberu, Y., \& Lily, B. B. (2018). Makna Ruang Dalam Budaya Masyarakat Sikka. Jurnal Arsitektur KOMPOSISI, Vol 12, No 2, Oktober 2018, 105-116.

Rosyadi. (2015). Tradisi Membangun Rumah Dalam Kajian Kearifan Lokal (Studi Kasus Pada Masyarakat Adat Kampung Dukuh). Jurnal Patanjala, Vol. 7, No. 3, September 2015, 415 - 430. 